\title{
Laser-Raman and FT-IR spectroscopic studies of peptide-analogues of silkmoth chorion protein segments
}

\author{
Dimitra C. Benaki a, Amalia Aggeli b, Georgios D. Chryssikos ${ }^{\mathrm{c}}$, Yiagos D. Yiannopoulos ${ }^{\mathrm{c}}$, \\ Efstratios I. Kamitsos ${ }^{\mathrm{c}}$, Elizabeth Brumley ${ }^{\mathrm{d}}$, Steven T. Case ${ }^{\mathrm{d}}$, Neville Boden ${ }^{\mathrm{b}}$, \\ Stavros J. Hamodrakas ${ }^{a}, *$ \\ a Department of Biology, Division of Cell Biology and Biophysics, University of Athens, Athens 15701, Greece \\ ${ }^{\mathrm{b}}$ Centre for Self-Organizing Molecular Systems, School of Chemistry, University of Leeds, Leeds LS2 9JT, UK \\ ${ }^{\mathrm{c}}$ Institute of Theoretical and Physical Chemistry, National Hellenic Research Foundation, Athens 11635, Greece \\ ${ }^{\mathrm{d}}$ Department of Biochemistry, The University of Mississippi Medical Center, Jackson, MS 39216-4505, USA
}

Received 10 September 1997; received in revised form 20 January 1998; accepted 22 February 1998

\begin{abstract}
Silkmoth chorion, the proteinaceous major component of the eggshell, with extraordinary mechanical and physiological properties, consists of a complex set of proteins, which have a tripartite structure: a central, evolutionarily conserved, domain and two more variable 'arms'. Peptide-analogues of silkmoth chorion protein central domain segments have been synthesized. Laser-Raman and infrared spectroscopic studies suggest the preponderance of antiparallel $\beta$-pleated sheet structure for these peptides, both in solution and in the solid state. (C) 1998 Elsevier Science B.V. All rights reserved.
\end{abstract}

Keywords: Structure; Peptide-analogues; Silkmoth chorion proteins; Laser-Raman spectroscopy; FT-IR spectroscopy

\section{Introduction}

Silkmoth chorion is the major component of the eggshell covering the oocyte and the developing embryo. It comprises a proteinaceous protective and functional layer with extraordinary mechanical properties and is an interesting model system in several current areas of biological research: cellular differentiation, molecular evolution and fibrous protein folding and self assembly (reviewed in [1-3]). Understanding the relationship between the structure, function and assembly of its component proteins might be fruitful in the design of novel biomaterials [3].

\footnotetext{
* Corresponding author. Tel.: + 301 7284545, 7240091; fax: + 301 7231634; e-mail: shamodr@atlas.uoa.gr
}

Biochemically, silkmoth chorion is surprisingly complex and about 200 proteins have been resolved by two-dimensional gel electrophoresis [1]. They were classified into a small number of families or classes called A, B and C. The gene families that encode these proteins are themselves related and constitute a superfamily with two branches, the $\alpha$-branch and the $\beta$-branch [4].

Amino acid sequence comparisons and predictions of protein secondary structure revealed that chorion proteins exhibit a tripartite structure: a central domain, evolutionarily conserved in each protein class (recognizably homologous among classes of the same branch) and two flanking Nand C-terminal domains or 'arms' which are more variable but marked by the presence of characteristic tandemly repetitive short peptides that do not appear in the central domain [5]. 


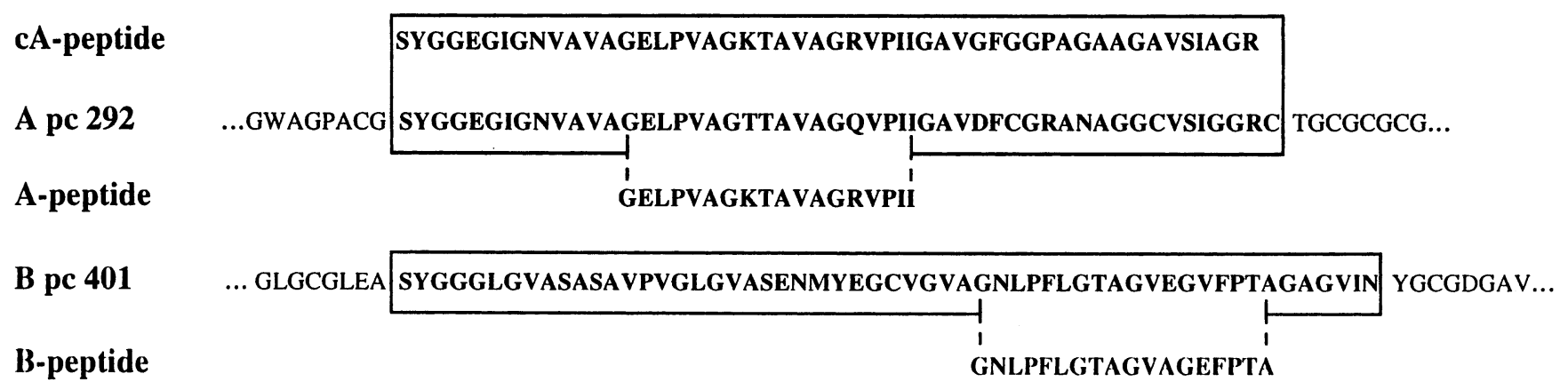

Fig. 1. Amino acid sequence of synthetic peptides and chorion proteins. The cA, A and B peptides and two typical chorion proteins, A pc292 and B pc401, (members of the A and B silkmoth chorion protein classes, respectively [1,3]), are shown for comparison (one-letter code). The central domain of each protein is boxed. Broken lines flank the portions of the sequence of the A and B proteins homologous to the peptides. Dots indicate that only parts of the protein sequence are presented.

A structural model has been proposed for the central domain and the flanking arms combining data from amino acid sequence comparisons, secondary structure prediction, analysis of amino acid periodicities and modelling [6,7]. According to this model chorion proteins adopt a characteristic antiparallel, most probably twisted, $\beta$-pleated sheet structure of four residue $\beta$-strands connected by $\beta$-turns $[6,7]$. Evidence from X-ray diffraction, laser-Raman, infrared and CD spectroscopy supports this model ([3] and references therein).

However, because of chorion complexity, it is very difficult to isolate and purify individual chorion proteins suitable for biophysical and biochemical studies. Therefore, an alternative approach was chosen in our attempts to elucidate the principles that govern chorion protein folding and assembly. Peptides thought to be representative of certain, structurally important, parts of chorion proteins have been synthesized and an effort is currently being made to study their structure both in solution and in the solid state. It is hoped that this analysis might reveal the folding and packing patterns significant in chorion protein structure and assembly.

For this study, three such peptides were synthesized: two 18-residue peptides were chosen to be analogues of parts of the central domain of the A and $\mathrm{B}$ classes of chorion proteins; the third, a 51-residue peptide, is an analogue of the entire central domain of the A class of the silkmoth chorion proteins. The logic behind this choice is the following: the A and B classes of chorion proteins are the most abundant, constituting $88 \%$ of the total chorion mass [1]. The peptides were chosen to represent either fragments or the entire central domain, since this part of the primary sequence exhibits evolutionary conservation and length invariance among the proteins of the same class. This suggests that it adopts a precise, functionally important, three-dimensional entity. Thus, it would be interesting to study the structure of either parts or the entire domain.

In this paper we present the results obtained from laser-Raman and infrared spectroscopic conformational studies of these synthetic chorion peptides.

\section{Materials and methods}

\subsection{Synthesis and purification}

\subsection{1. $A$ and $B$ peptides}

Solid-phase peptide synthesis [8] was done on an Applied Biosystems model 430A automated peptide synthesizer using standard cycles for t-BOC chemistry. The side-chain protecting groups were removed and the peptides were cleaved from the support resin with a mixture of anhydrous hydrofluoric acid-anisole-dimethyl sulfide (10:1:1), as described in [9]. The resulting peptide-resin mixture was resuspended in 30\% acetic acid, repeatedly extracted with petroleum ether, filtered to remove any remaining resin, frozen and lyophilized. Any remaining traces of scavengers were removed by resuspending the peptides in $5 \%$ acetic acid and chromatographing them twice on a $3 \mathrm{~cm} \times 50 \mathrm{~cm}$ column of Sephadex G-25 using 10 $\mathrm{mM}$ triethylene bicarbonate, $\mathrm{pH} 7.5$, as the mobile phase. Final peptide-containing peaks appeared homogeneous by HPLC and had the predicted amino acid compositions (data not shown). For further use, the buffer was removed from the 
Table 1

Wavenumbers and tentative assignments of bands in the laser-Raman spectra of the A, B and cA peptide analogues of silkmoth chorion protein fragments.

\begin{tabular}{|c|c|c|c|}
\hline \multicolumn{3}{|c|}{ Wavenumber $\left(\mathrm{cm}^{-1}\right)$} & \multirow[t]{2}{*}{ Tentative assignment } \\
\hline A peptide & B peptide & cA peptide & \\
\hline - & $622(+)$ & & Phe \\
\hline - & 854 & 850 & Phe, Tyr \\
\hline - & $1003(+)$ & 1003 & Phe \\
\hline - & $1031(+)$ & 1031 & Phe \\
\hline - & 1204 & - & Phe \\
\hline $1247(+)$ & $1250(+)$ & $1240(+)$ & Amide III (antiparallel $\beta$-sheet) \\
\hline 1273 & 1275 & 1269 & Amide III ( $\beta$-turns)? \\
\hline 1318 & 1319 & - & Amide III ( $\beta$-turns)? \\
\hline 1344 & 1344 & 1337 & Amide III ( $\beta$-turns)? \\
\hline $1452(+)$ & $1452(+)$ & $1452(+)$ & $\mathrm{CH}_{2}$ deformation \\
\hline \multirow[t]{2}{*}{-} & - & 1557 & Amide II ( $\beta$-turns)? \\
\hline & $1603(+)$ & 1616 & Phe, Tyr \\
\hline $1673(+)$ & $1673(+)$ & $1670(+)$ & Amide I (antiparallel $\beta$-sheet) \\
\hline
\end{tabular}

(+) Denotes a strong peak.

peptides by repeated lyophilization and dissolution in water.

\subsection{2. cA peptide}

Solid-phase peptide synthesis was performed on an Applied Biosystems model 431A peptide synthesizer using Fmoc/tBu chemistry. After synthesis was completed, the protecting groups were removed and the peptide chains were cleaved from the resin with a mixture of trifluoroacetate (TFA)-phenol-EDT-thioanisole-water $(10 \mathrm{ml}$, $0.75 \mathrm{~g}, 0.25 \mathrm{ml}, 0.5 \mathrm{ml}, 0.5 \mathrm{ml}$ ) for $3 \mathrm{~h}$. The peptide was purified on a Vydac $\mathrm{C}-18$ reversed phase column $(20 \mathrm{~mm} \times 250 \mathrm{~mm}, 0.010 \mathrm{~mm}$ particle $)$ at a flow rate of $10 \mathrm{ml} / \mathrm{min}$. Solvent $A$ was water containing $0.1 \%$ TFA and solvent B was $70 \%$ acetonitrile, $0.1 \%$ TFA in water. Peptide homogeneity $(>99 \%$ ) was determined by HPLC using an acetonitrile gradient of $0.7 \%$ per min. The peptide composition was confirmed by amino acid analysis and the molecular weight was checked by matrix-assisted laser desorption ionisation time-offlight mass spectrometry.

\subsection{Laser-Raman spectroscopy}

The lyophilized and thoroughly dried peptide samples were packed into quartz capillaries sealed at both ends.

The $488 \mathrm{~nm}$ line of a Spectra Physics 165 argonion laser, operating at $150 \mathrm{~mW}$ was used as the excitation source and a $90^{\circ}$ scattering geometry to the capillaries was employed. Raman spectra were recorded on a Ramanor HG2S Jobin-Yvon spectrometer. To reduce the noise level, the spectra were recorded at a scanning speed of $100 / \mathrm{cm} / \mathrm{min}$ and a time constant of $2 \mathrm{~s}$. The spectral resolution was $5 \mathrm{~cm}^{-1}$.

Several attempts to obtain Raman spectra from aqueous solutions of the peptide samples were not successful because of high fluorescent background.

\subsection{FT-IR spectroscopy}

Three types of FT-IR experiments were carried out:

(A) The samples for IR spectroscopy were in the form of solid $\mathrm{KBr}$ pellets. The lyophilized peptides were thoroughly dried and mixed with $\mathrm{KBr}$ to a final concentration of approximately $2 \%$ $(\mathrm{w} / \mathrm{w})$. IR spectra were recorded on a FT-IR Bruker $113 \mathrm{v}$ vacuum spectrometer. Each spectrum is the result of signal-averaging of 100 scans at a resolution of $2 \mathrm{~cm}^{-1}$.

(B) The spectra of dry peptides were collected by depositing a thin, homogeneous film of dry peptides between $\mathrm{CaF}_{2}$ crystals.

(C) The peptide solutions were prepared in $\mathrm{D}_{2} \mathrm{O}$ ( $>99.8 \%$ pure). The peptide concentration was determined by weighing.

Low concentration peptide samples (i.e. $5 \mathrm{mg}$ $\mathrm{cA} / \mathrm{ml} \mathrm{D}_{2} \mathrm{O}, 5 \mathrm{mg} \mathrm{A} / \mathrm{ml} \mathrm{D}_{2} \mathrm{O}$ and $3 \mathrm{mg} \mathrm{B} / \mathrm{ml} \mathrm{D}_{2} \mathrm{O}$ ) 

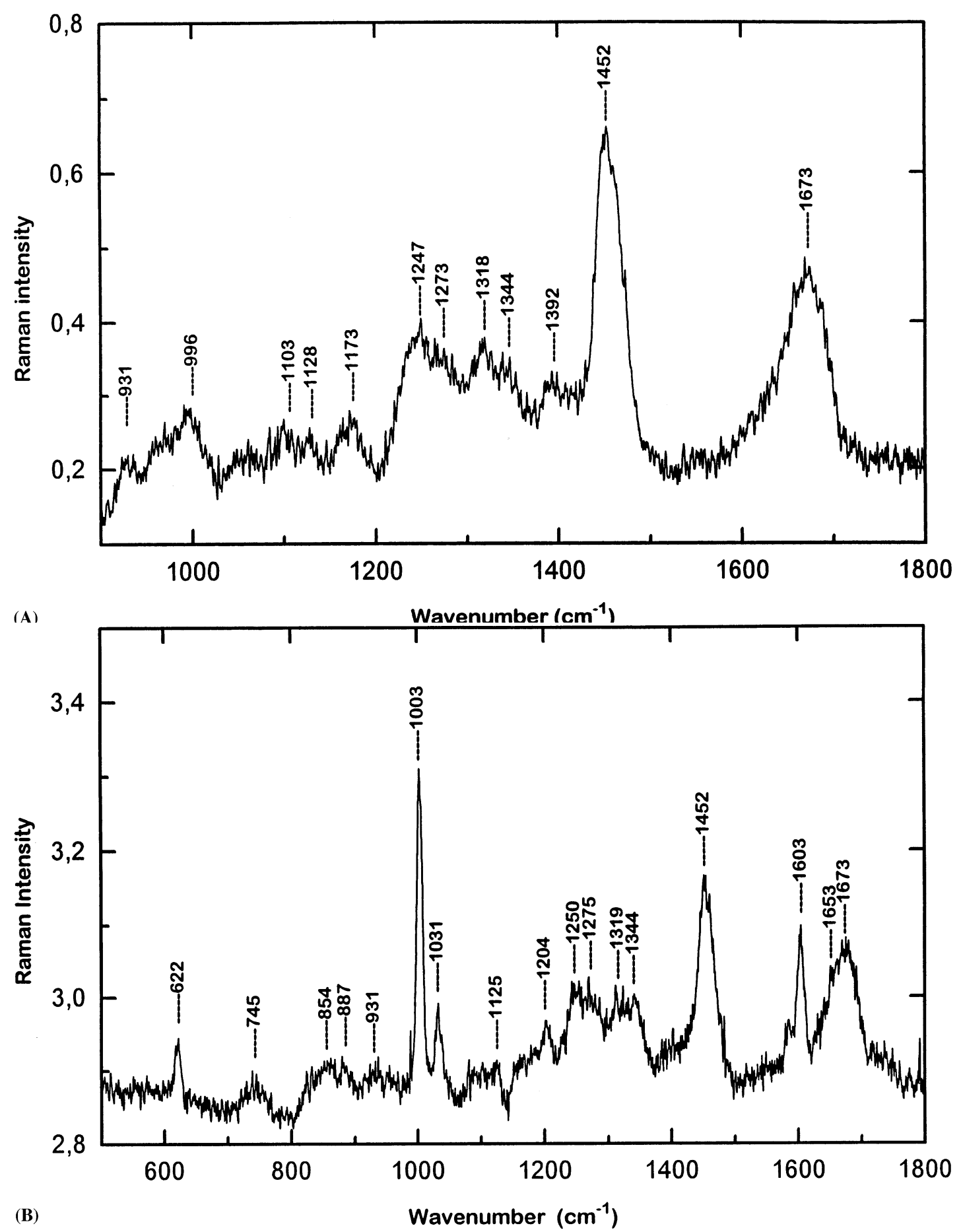

Fig. 2. Laser-Raman spectra obtained from the A peptide (A), B peptide (B) and cA peptide (C). Lyophilized and thoroughly dried peptide samples were packed into quartz capillaries sealed at both ends. A $90^{\circ}$ scattering geometry to the capillaries was employed. Instrumental conditions: excitation wavelength, $488 \mathrm{~nm}$; scanning speed, 100/cm/min; time constant, 2 s; spectral resolution $5 \mathrm{~cm}^{-1}$; operating laser power $150 \mathrm{~mW}$.

were allowed to equilibrate for 4 days at room temperature. A demountable $\mathrm{CaF}_{2}$-based FT-IR cell, $0.1 \mathrm{~mm}$ thick, was used. A and $\mathrm{cA}$ formed transparent samples, whilst B was a precipitate. High concentration peptide samples (i.e. ca. 50 $\mathrm{mg} \mathrm{cA} / \mathrm{ml} \mathrm{D}_{2} \mathrm{O}, 50 \mathrm{mg} \mathrm{A} / \mathrm{ml} \mathrm{D}_{2} \mathrm{O}$ and $30 \mathrm{mg} \mathrm{B} / \mathrm{ml}$ $\mathrm{D}_{2} \mathrm{O}$ ), were prepared by placing dry peptide on a $\mathrm{CaF}_{2}$ crystal followed by addition of $10 \mu 1 \mathrm{D}_{2} \mathrm{O}$, mixing, and subsequent data collection. No changes were observed in the spectra over a $24 \mathrm{~h}$ period. 


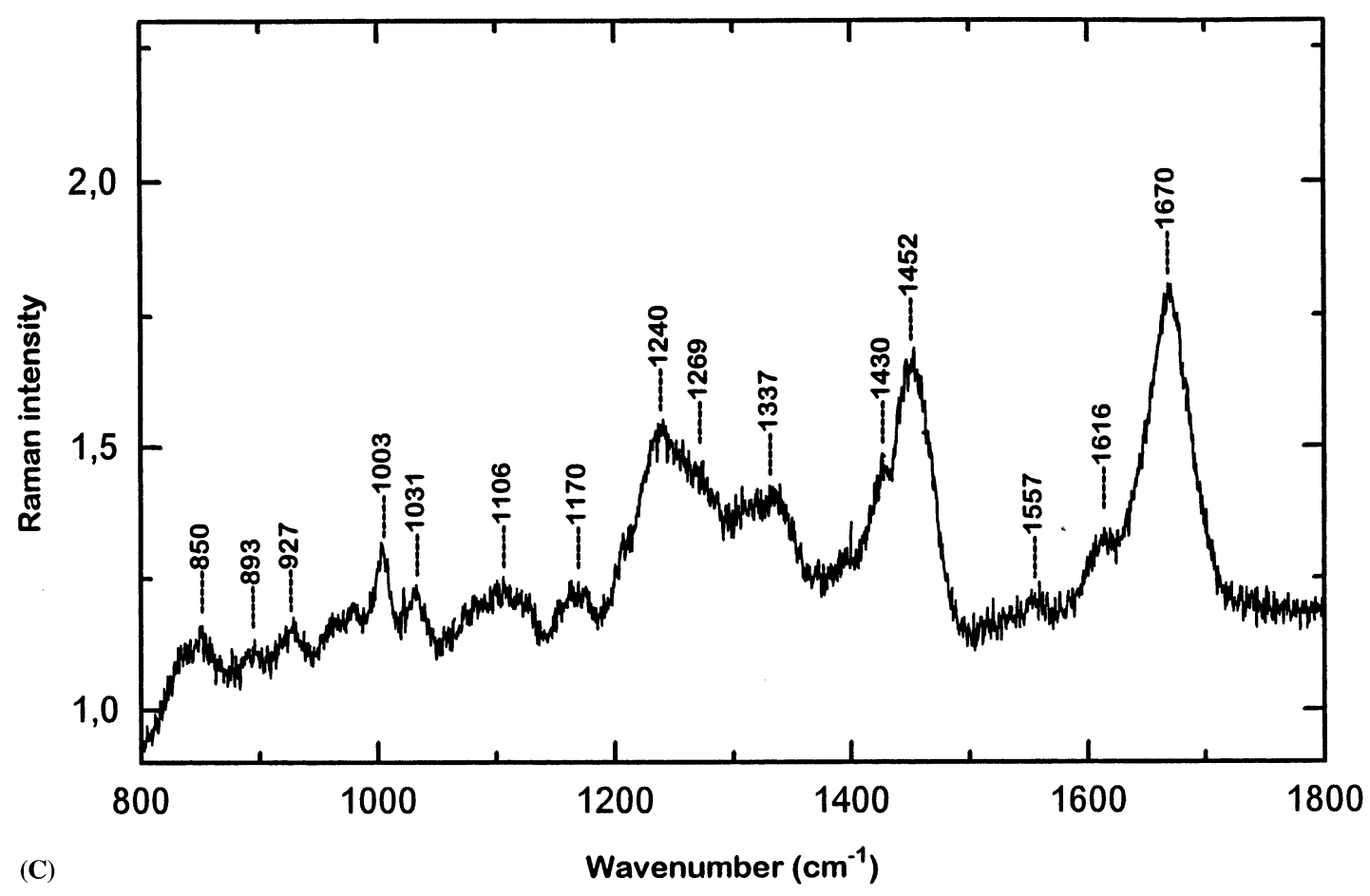

Fig. 2. (Continued)

Spectra for the $\mathrm{B}$ and $\mathrm{C}$ types of experiments were run on a Perkin-Elmer 1760X FT-IR spectrometer at room temperature. The instrument resolution was set at $4 \mathrm{~cm}^{-1}$, apart from the high concentration spectra of peptides A and cA, for which the resolution was set at $2 \mathrm{~cm}^{-1}$. All spectra are absorbance spectra after solvent subtraction.

Smoothening of spectra was carried out with a step of 11 or 13 datapoints, using the SavitzkyGolay function [10].

Second derivatives of the spectra were obtained using a step of 13 datapoints to identify discrete absorption bands that make up the complex amide I profile. To avoid the significant edge effects possible in the derivative spectra, as distortions are induced, a wider spectral region than amide I was subjected to differentiation.

Quantitative analysis of the individual component bands of amide I was achieved, utilizing the program ORIGIN (MicroCal Software). Curvefitting of the FT-IR spectra was performed by manual, iterative adjustment of the relative height, width and relative ratios of Lorentzian and/or Gaussian functions of the line shape of the individual component bands identified after differentiation, until the line shape of amide I calculated by the program was judged to be approximately the same as the experimental spectrum by least squares. The integrated area under each compo- nent band, after the last iteration, was calculated as a percentage of the total amide I area, and this value was taken to be the percentage of the particular secondary structure present in the protein.

\section{Results}

\subsection{Peptide design}

Three peptides, representative of the silkmoth chorion protein segments, were synthesized (Fig. 1).

1. The A peptide, which has a sequence representative of a part of the central domain of the A silkmoth chorion protein class.

2. The B peptide, which has a sequence representative of a part of the central domain of the $\mathrm{B}$ silkmoth chorion protein class.

3. The cA peptide, with a sequence representative of the entire central domain of the A silkmoth chorion protein class.

\subsection{Raman spectra}

Table 1 shows the most prominent bands and their tentative assignments in the laser-Raman spectra of the A, B and cA peptides. Additional peaks are resolved but not tabulated because in- 

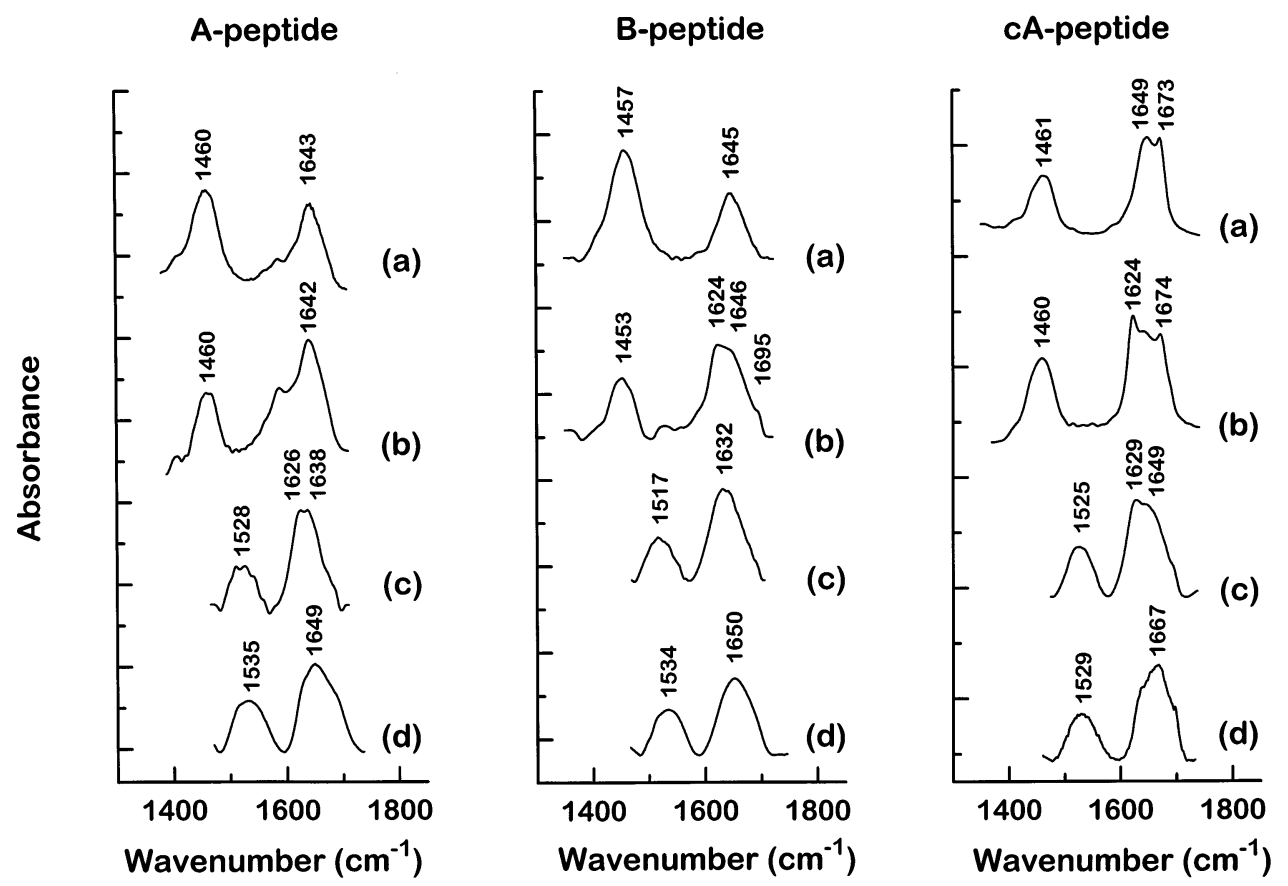

Fig. 3. FT-IR spectra of the A, B and cA peptide. (a) Low concentration peptide samples in $\mathrm{D}_{2} \mathrm{O}(5 \mathrm{mg} \mathrm{A} / \mathrm{ml}, 3 \mathrm{mg} \mathrm{B} / \mathrm{ml}$ and $5 \mathrm{mg} \mathrm{cA} / \mathrm{ml}$ ). (b) High concentration peptide samples in $\mathrm{D}_{2} \mathrm{O}(50 \mathrm{mg} \mathrm{A} / \mathrm{ml}, 30 \mathrm{mg} \mathrm{B} / \mathrm{ml}$ and $50 \mathrm{mg} \mathrm{cA} / \mathrm{ml})$. (c) Dried (lyophilized) peptide samples. Spectral resolution for (a) and (c) $4 \mathrm{~cm}^{-1}$, for (b) $2 \mathrm{~cm}^{-1}$. (d) Samples were in the form of $\mathrm{KBr}$ pellets, containing about $2 \%(\mathrm{w} / \mathrm{w})$ peptide, thoroughly dried before mixing with $\mathrm{KBr}$. The spectra are the result of signal averaging of 100 scans, at $2 \mathrm{~cm}^{-1}$ resolution.

sufficient data was available for unambiguous assignments.

In the laser-Raman spectra of both $\mathrm{A}$ and $\mathrm{B}$ peptides (Fig. 2a and b) the appearance of the amide I band at $1673 \mathrm{~cm}^{-1}$ suggests the presence of $\beta$-sheet conformation [11-13]

The presence of strong features in the 1230$1350 \mathrm{~cm}^{-1}$ (amide III region) indicates absence of $\alpha$-helical conformation in both peptides [11-13].

In the amide III region, bands at 1247 and 1250 $\mathrm{cm}^{-1}$ for the A and B peptides are seen respectively. These bands are centered at wavenumbers somewhat higher than is usually agreed upon for amide III bands that are signatures of $\beta$-sheet conformation; however similar bands due to $\beta$ sheet structure have been reported ([13] and the references therein). Alternatively, they might indicate contribution from unordered structure or $\beta$ turns [11-13].

Bands at ca. 1273, 1320 and $1340 \mathrm{~cm}^{-1}$ in both A and B peptide spectra may be caused by the presence of $\beta$-turns [15]. Since the signatures for $\beta$-turns are not generally agreed upon we shall not attempt to attribute them to any defined secondary structure.

Comparing the Raman spectra of the $\mathrm{A}$ and $\mathrm{B}$ peptides in the region from 600 to $1800 \mathrm{~cm}^{-1}$ it is seen that additional prominent bands are observed at $622,1003,1031$ and $1603 \mathrm{~cm}^{-1}$ in the spectrum of the B peptide. These are most likely due to Phe residues which are present in the $\mathrm{B}$ peptide but absent in the A peptide [11-13].

The laser-Raman spectrum of the $\mathrm{cA}$ peptide (Fig. 2c) indicates that this peptide also adopts a $\beta$-sheet conformation. In fact, the appearance of the amide I band at $1670 \mathrm{~cm}^{-1}$ and the amide III band at $1240 \mathrm{~cm}^{-1}$ strongly suggest abundant $\beta$-pleated sheet structures that appear to be uniform (half width of the amide I band ca. 40 $\mathrm{cm}^{-1}$ ). The bands at 1003 and $1031 \mathrm{~cm}^{-1}$ are ascribable to Phe whereas the bands at 850 and $1616 \mathrm{~cm}^{-1}$ are most likely due to Tyr; the latter may also have a contribution from Phe (the cA peptide contains both Phe and Tyr residues in its sequence).

\subsection{FT-IR spectra}

The FT-IR spectra of the A, B and cA peptides are shown in Fig. 3. As described in Section 2, they were obtained, from low concentration solutions of the peptides in $\mathrm{D}_{2} \mathrm{O}$ (Fig. 3a), high concentration solutions in $\mathrm{D}_{2} \mathrm{O}$ (Fig. $3 \mathrm{~b}$ ), dry peptides (Fig. 3c) and $\mathrm{KBr}$ pellets (Fig. 3d). Table 2 shows 
Table 2

Amide I decomposition of the FT-IR spectra for the A, B and cA peptide analogues of silkmoth chorion protein fragments

\begin{tabular}{|c|c|c|c|c|}
\hline \multicolumn{4}{|l|}{ Band position $\left(\mathrm{cm}^{-1}\right)$} & \multirow[t]{2}{*}{ Tentative assignment } \\
\hline In $\mathrm{D}_{2} \mathrm{O}$ (low conc.) & In $\mathrm{D}_{2} \mathrm{O}$ (high conc.) & Solid & $\mathrm{KBr}$ pellet & \\
\hline \multicolumn{5}{|l|}{ A peptide } \\
\hline $1625,1638(48 \%)$ & $1613,1638(62 \%)$ & $1619,1625,1639(69 \%)$ & $1627(23 \%)$ & $\beta$-Sheet \\
\hline $1649(26 \%)$ & $1648(10 \%)$ & $1656(17 \%)$ & $1648(28 \%)$ & $\begin{array}{l}\text { Unordered } \\
\alpha \text {-Helix and/or large loops }\end{array}$ \\
\hline $1661(15 \%)$ & $1662(17 \%)$ & & $1665(17 \%)$ & $\beta$-Turns \\
\hline $1677(10 \%)$ & $1676(11 \%)$ & $1673(12 \%)$ & $1680(8 \%)$ & $\beta$-Turns $/ \beta$-sheet \\
\hline $\begin{array}{l}1693(1 \%) \\
\quad \beta \text {-Sheet }(\%)\end{array}$ & & $1687(2 \%)$ & $1692(24 \%)$ & Antiparallel $\beta$-sheet \\
\hline $\begin{array}{l}49-59 \\
\quad \beta \text {-Turns }+ \text { coil }(\%)\end{array}$ & $62-73$ & $71-83$ & $47-55$ & \\
\hline $41-51$ & $27-38$ & $17-29$ & $45-53$ & \\
\hline \multicolumn{5}{|l|}{$B$ peptide } \\
\hline $1619,1633(39 \%)$ & $1618(32 \%)$ & $1619,1630(35 \%)$ & $1614,1630(22 \%)$ & $\beta$-Sheet \\
\hline $1646(23 \%)$ & $1648(52 \%)$ & $1645(37 \%)$ & $1650,1655(46 \%)$ & $\begin{array}{l}\text { Uunordered } \\
\alpha \text {-Helix and/or large loops }\end{array}$ \\
\hline $1662(21 \%)$ & $1668(5 \%)$ & $1663(14 \%)$ & $1667(5 \%)$ & $\beta$-Turns \\
\hline $1677(12 \%)$ & $1682(6 \%)$ & $1679(12 \%)$ & $1679(19 \%)$ & $\beta$-Turns $/ \beta$-sheet \\
\hline $\begin{array}{l}1690(5 \%) \\
\quad \beta \text {-Sheet }(\%)\end{array}$ & $1696(5 \%)$ & $1693(2 \%)$ & $1692(8 \%)$ & Antiparallel $\beta$-sheet \\
\hline $\begin{array}{l}44-56 \\
\quad \beta \text {-Turns }+ \text { coil }(\%)\end{array}$ & $37-43$ & $37-49$ & $30-49$ & \\
\hline $44-56$ & $57-63$ & $51-63$ & $51-70$ & \\
\hline \multicolumn{5}{|l|}{ cA peptide } \\
\hline 1611 & & & 1612 & Tyr \\
\hline $1627(22 \%)$ & $1621(38 \%)$ & $1621,1631(34 \%)$ & $1628,1636(29 \%)$ & $\beta$-Sheet \\
\hline $1645(60 \%)$ & $1644(48 \%)$ & $1649(43 \%)$ & $1653(42 \%)$ & $\begin{array}{l}\text { Unordered } \\
\alpha \text {-Helix and/or large loops }\end{array}$ \\
\hline $1660(18 \%)$ & $1660(6 \%)$ & $1667(8 \%)$ & & $\beta$-Turns \\
\hline 1673 & 1674 & $1681(10 \%)$ & 1671 & $\begin{array}{l}\text { TFA } \\
\beta \text {-Turns } / \beta \text {-sheet }\end{array}$ \\
\hline & $1691(8 \%)$ & $1696(5 \%)$ & $1687,1699(29 \%)$ & Antiparallel $\beta$-sheet \\
\hline$\beta$-Sheet $(\%)$ & & & & \\
\hline${ }^{22} \beta$-Turns + coil $(\%)$ & 46 & $39-49$ & 58 & \\
\hline 78 & 54 & $51-61$ & 42 & \\
\hline
\end{tabular}

Experimental conditions as in Fig. 3. Individual components were identified from second-derivative spectra. Curve fitting was carried out assuming Gaussian/Lorentzian band shapes for individual components. Tentative assignments of individual bands were made according to [14-19]. Predicted secondary structure content, in parentheses, was estimated as described in Section 2 and Fig. 4. Predicted total secondary structure estimates are also given for $\beta$-sheet and $\beta$-turns + coil, for clarity.

the bands identified in the second derivative specetra of the peptides in the amide I region, their tentative assignments [15-17], and predicted secondary structure quantitative estimates, after the curve-fitting procedure of the amide I band from its constituent component bands, as described in Section 2. The amide I curve-fitting analysis of the FT-IR spectra from peptide cA is shown in Fig. 4, for clarity.

Obviously, the peptides do not adopt any sig- nificant amounts of $\alpha$-helical conformation both in solution and in the solid state. However, large amounts of $\beta$-sheet structure are seen, both in solution and in the solid state (usually more than $40 \%$ ), with significant contribution from $\beta$-turns and random coil (unordered) structures.

Amide groups in $\beta$-pleated sheets give rise to highly diagnostic bands between approximately 1620 and $1640 \mathrm{~cm}^{-1}$ [15-20], although in some cases ' $\beta$-bands' are shifted even below $1620 \mathrm{~cm}^{-1}$ 


\section{cA-peptide}
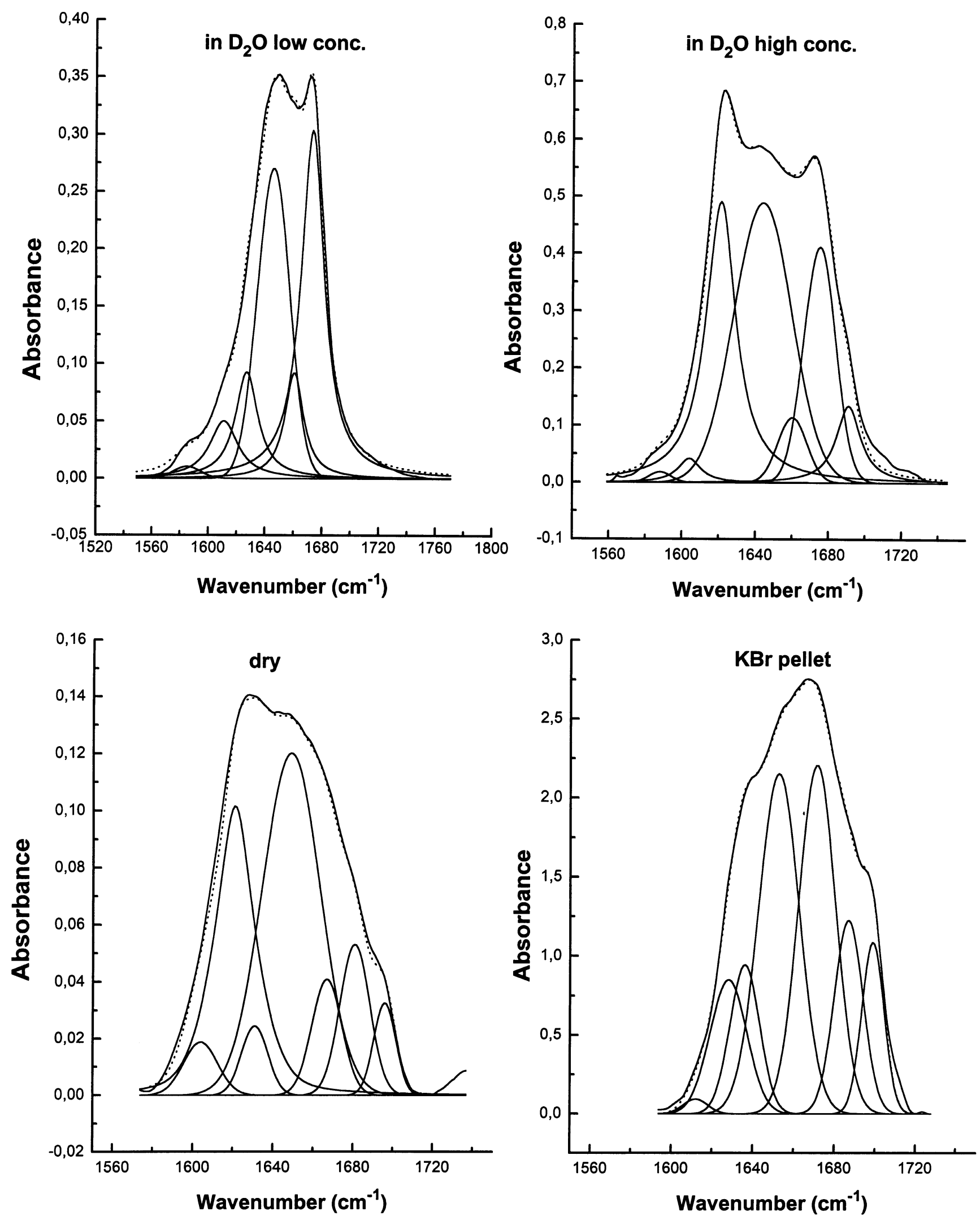
[21]. For many proteins more than one component is observed in the $1620-1640 \mathrm{~cm}^{-1}$ region. The multiplicity reflects differences in hydrogen bonding strength as well as differences in transition dipolecoupling in different $\beta$-strands and is of potential diagnostic value [20]. The observation in the IR spectra of proteins of a high wavenumber ' $\beta$-component', in the region ca. $1690-1700 \mathrm{~cm}^{-1}$, suggests that the $\beta$-sheets are antiparallel [15-20].

In our case (Figs. 3 and 4 and Table 2), usually more than one strong component band is observed in the $1620-1640 \mathrm{~cm}^{-1}$ region for all peptides in solution and in the solid state. Their exact location varies from peptide to peptide, but it is seen that the IR spectra from the $\mathrm{B}$ and $\mathrm{cA}$ peptides have, apparently, lower wavenumber components than the A-peptide, which probably indicates stronger hydrogen bonding. Component bands situated in the region 1690-1700 $\mathrm{cm}^{-1}$, approximately, usually seen as shoulders in the original FT-IR spectra (Figs. 3 and 4 and Table 2), strongly suggest an antiparallel $\beta$-sheet structure [15-20] present in all peptides both in solution and in the solid state. With the possible exception of the B peptide, which it should be noted, tends to precipitate at high concentrations, it appears that increasing peptide concentration results in an increased amount of $\beta$-sheet structure. We interpret these results as being due to the presence of intermolecular $\beta$-sheet structures, which, most probably, become more stable, as peptide concentration increases.

$\beta$-Turns are also present in solution and in the solid state structure of all peptides as can be judged from the appearance of bands in the 1660-1680 $\mathrm{cm}^{-1}$ region [15-20]. Together with the presence of significant amounts of random coil suggested by the bands in the $1645-1650 \mathrm{~cm}^{-1}$ region, they account for the remainder of the structure.

\section{Discussion}

We have undertaken the study of the structure of the peptides representative of segments of the silkmoth chorion proteins in the hope that these studies will reveal their intrinsic propensities towards fold- ing patterns similar to those that exist in vivo.

Neither solid state, nor solution studies can be performed under conditions precisely mimicking the environment of chorion proteins in vivo. Moreover, the structures acquired for the peptides lack the context of the remainder of the protein [19]. In spite of these limitations the data presented here represent the first step to the only systematic approach available for deducing the structure of proteins such as silkmoth chorion proteins, that are not available in suitable quantities, or amenable to traditional purification. However, since the physiological environment of chorion proteins is not known, peptides were initially studied both in the solid state and in solution. It is well known that small peptides may rapidly interconvert between a variety of structural forms in solution [19], and our preliminary NMR studies indicate that this is, indeed, the case, at least for the $\mathrm{A}$ and $\mathrm{B}$ peptides (Benaki et al., in preparation). Nevertheless, a common molecular denominator appears to be dominant in these structural forms, the structure of antiparallel $\beta$-pleated sheet.

Laser-Raman and IR spectroscopy were used since these vibrational spectroscopies provide complementary information concerning the conformation of polypeptides and proteins [16,23]. One obvious conclusion that can be drawn from this work is that all peptides studied to date contain significant amounts of antiparallel $\beta$-pleated sheet conformation in solution and in the solid (lyophilized) state. Though lyophilization may increase the $\beta$-sheet structure content of globular proteins [22], similar data are lacking for structural proteins. Nonetheless, our conclusion agrees with secondary structure prediction and modelling studies $[5,6]$ and biophysical data acquired for silkmoth chorion proteins ([3] and the references therein).

There is a distinct difference between laser-Raman and FT-IR spectroscopy. Water absorbs strongly at ca. $1650 \mathrm{~cm}^{-1}$, i.e. in the amide I region in the IR spectra, due to the strong $\mathrm{O}-\mathrm{H}$ bending absorption at $1644 \mathrm{~cm}^{-1}[16,19,23]$. This obscures the amide I region and makes the IR spectra less amenable to interpretation than the Raman spectra where water does not interfere [16,23]. For this

Fig. 4. Amide I band decomposition of the FT-IR spectra from the cA peptide. Experimental conditions as in Fig. 3. Curve fitting was carried out assuming Gaussian/Lorentzian band shapes for individual component bands (solid lines) identified from second-derivative spectra (see Table 2) as described in Section 2. The solid line is the original spectrum whereas the dotted line is the result of the superposition of individual components. The calculation of secondary structure content was performed as described in Section 2. Bands due to TFA at ca. $1670 \mathrm{~cm}^{-1}$, were not taken into account. 
reason we have chosen to obtain FT-IR spectra of the peptides in $\mathrm{D}_{2} \mathrm{O}$ solutions which do not have spectral interference of water in the amide I region. The differences observed in the FT-IR spectra of the dried peptides and in the form of $\mathrm{KBr}$ pellets are most probably due to traces of water absorbed by the $\mathrm{KBr}$ pellets, which cannot be removed even under the most stringent conditions used to dry the pellets [16].

Another point that should be discussed further is the appearance of a very strong absorption band at ca. $1670 \mathrm{~cm}^{-1}$ in the IR spectra of the cA peptide which is not observed in the IR spectra of the A and $B$ peptides. It might erroneously be assumed that this band may be due to $\beta$-turns or perhaps the antiparallel $\beta$-sheet which exists in the structure as can be judged from the laser-Raman spectra evidence. However, the different synthesis and purification procedure for this peptide which involved TFA should also be taken into account. It has been pointed out by several authors $[20,24]$ that this counterion absorbs strongly at ca. $1670 \mathrm{~cm}^{-1}$, in the presence of water, and this band may be due to its remaining traces. In agreement with this interpretation is the fact that the FT-IR spectrum of the dried cA peptide shows minimal TFA interference (Fig. $3)$.

The A and B peptides apparently adopt different conformations in water as demonstrated by their different maxima of IR absorption (Fig. 3 and Table 2). Furthermore, the A peptide is highly soluble in aqueous environments, whilst B is only sparingly soluble in water. Both peptides have the same length, are highly homologous in their primary structure (Fig. 1) and have similar overall hydrophobicity. The main difference is that $\mathrm{A}$ has a higher density of charged groups than B. This difference may influence decisively the intramolecular folding patterns as well as the supramolecular arrangement of the two peptides in water. The comparison shows that subtle differences in electrostatic interactions at the intramolecular or intermolecular level may lead to different folding/packing patterns of highly homologous segments of chorion proteins.

Although it is true that amide I differentiation and deconvolution should always be handled with care [19], so that the values reported in Table 2 should only be considered as indicative, evidence both from the laser Raman spectra and the FT-IR spectra clearly indicates the preponderance of an antiparallel $\beta$-pleated sheet structure in the conformation of the peptides studied in solution and in the solid state.
2D-NMR work is currently being performed on these peptides in solution, to reveal the structural characteristics at higher resolution. How close is the structure of these peptides to the $\beta$-sheet models proposed for chorion proteins [3] remains to be seen.

\section{Acknowledgements}

SJH thanks the University of Athens for financial support. STC wishes to thank the US Office of Naval Research (Contract \# N00014-87-K-0387) and Army Research Office (Grant \# DAAL03-91G-0239) for financial support. We thank Dr A. Pastore for critically reading the manuscript. We also thank Professor F.C. Kafatos and Dr W. Ansorge for their help in the synthesis of the $\mathrm{cA}$ peptide.

\section{References}

[1] Regier JC, Kafatos FC. In: Gilbert LI, Kerkut GA, editors. Comprehensive Insect Biochemistry, Physiology and Pharmacology, vol. I. Oxford: Pergamon Press, 1985:113-151.

[2] Goldsmith MR, Kafatos FC. Annu Rev Genet 1984; 18:443-87.

[3] Hamodrakas SJ. In: Case ST, editor. Results and Problems in Cell Differentiation, vol. 19, chap. 6. Berlin: Springer, 1992:115-186.

[4] Lekanidou R, Rodakis GC, Eickbush TH, Kafatos FC. Proc Natl Acad Sci USA 1986;83:6514-8.

[5] Hamodrakas SJ, Jones CW, Kafatos FC. Biochim Biophys Acta 1982;700:42-51.

[6] Hamodrakas SJ, Etmektzoglou T, Kafatos FC. J Mol Biol 1985;186:583-9.

[7] Hamodrakas SJ, Bosshard HE, Carlson CN. Protein Eng. 1988;2(3):201-7.

[8] Marglin A, Merrifield RB. Annu Rev Biochem 1970;39:841-66.

[9] Tam JP, Heath WF, Merrifield RB. J Am Chem Soc 1983;105:6442-55.

[10] Savitsky A, Golay MJE. Anal Chem 1964;36:1627-39.

[11] Frushour BG, Koening JL. In: Clark RJH, Hester RE, editors. Advances in Infrared and Raman Spectroscopy, vol. 1. London: Heyden, 1975:35-97.

[12] Spiro TG, Gaber BP. Annu Rev Biochem 1977;46:553-72.

[13] Yu NT. CRC Crit Rev Biochem 1977;4:229-80.

[14] Hamodrakas SJ, Kamitsos EI, Papadopoulou PG. Biochim Biophys Acta 1987;913:163-9.

[15] Bandekar J, Krimm S. Proc Natl Acad Sci USA 1979;76:774-7.

[16] Parker FS. Applications of Infrared, Raman, and Resonance Raman Spectroscopy in Biochemistry. New York: Plenum, 1983. 
[17] Byler DM, Susi H. Biopolymers 1986;25:469-87.

[18] Arrondo JLR, Young NM, Mantsch HH. Biochim Biophys Acta 1988;952:261-8.

[19] Jackson M, Mantsch HH. Crit Rev Biochem Mol Biol 1995;30(2):95-120.

[20] Surewicz WK, Mantsch HH, Chapman D. Biochemistry 1993;32(2):389-94.

[21] Surewicz WK, Mantsch HH. Biochim Biophys Acta
1988;952:115-30.

[22] Griebenow K, Klibanov AM. Proc Natl Acad Sci USA 1995;92:10969-76.

[23] Carey PR. Biochemical Applications of Raman and Resonance Raman Spectroscopies. New York: Academic Press, 1982.

[24] Haris P, Chapman D. Biopolymers (Pept Sci) 1995;37:251-63. 